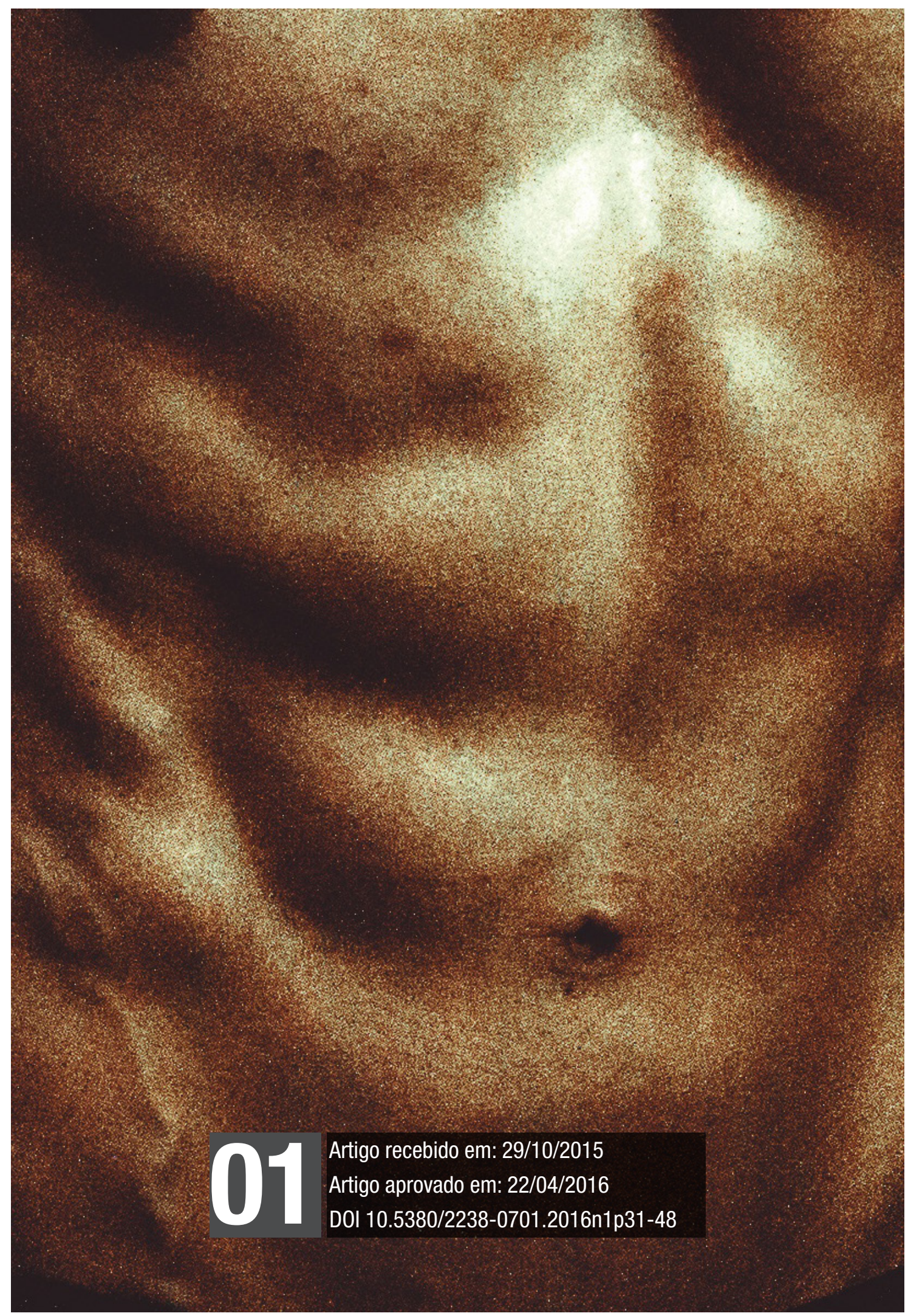


Corpo. Mídia. Representação Social. Biopoder.

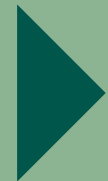




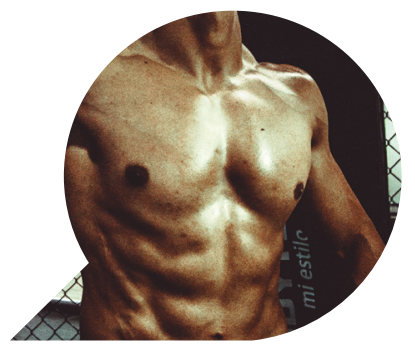

\title{
O corpo na esfera da mídia: entre representações sociais e biopoder
}

\author{
The body in the media sphere: \\ between social representations and biopower \\ El cuerpo en la esfera de los medios: \\ entre las representaciones sociales y biopoder
}

\section{JEFERSON BERTOLINI *}

Resumo: Este artigo discute o corpo, tema atualmente em voga nos meios de comunicação, em duas perspectivas: das representações sociais e do biopoder. O texto aponta que os programas que ensinam como comer, como se exercitar, como perder peso e afins criam uma representação social do corpo como algo que deve ser constantemente cuidado e melhorado. Essa representação tem uma face ingênua, pois assimila passivamente técnicas do biopoder, que objetiva produzir corpos economicamente ativos e politicamente dóceis. $\mathrm{O}$ artigo adota técnica interdisciplinar para associar temas da Comunicação Social, da Psicologia Social e da Filosofia.

Palavras-chave: Corpo; Mídia; Representação social; Biopoder.

* Doutorado Interdisciplinar em Ciências Humanas (UFSC); mestrado em Jornalismo (UFSC); bacharelado em Comunicação Social/Jornalismo (Univali). 


\begin{abstract}
This article discusses the body subject in vogue in the mass media, in two different perspectives: the social representations and biopower. The text states that programming creates a social representation of the body as something that must be constantly maintained and improved; this representation is a naive face because it treats passively techniques of biopower, which aims to produce economically active and politically docile bodies. The manuscript adopts interdisciplinary technique for associating themes of Social Communication, Social Psychology and Philosophy.
\end{abstract}

Keywords: Body; Media; Social representation; Biopower.

Resumen: Este artículo aborda el cuerpo tema en boga en los medios de comunicación, en dos perspectivas diferentes: las representaciones sociales y el biopoder. El texto afirma que la programación crea una representación social del cuerpo como algo que debe ser constantemente mantenido y mejorado; esta representación es un sesgo ingenua porque trata las técnicas pasivamente de biopoder, que tiene como objetivo producir cuerpos económicamente activas y políticamente dóciles. El manuscrito adopta la técnica interdisciplinaria para asociar temas de Comunicación Social, Psicología Social y Filosofía.

Palabras clave: Cuerpo; Medios; Representación social; Biopoder. 


\section{Introdução}

Programas que valorizam os cuidados com o corpo têm ocupado grande destaque na mídia brasileira ${ }^{1}$ nos últimos anos. Eles ensinam como perder peso; alertam sobre o risco da gordura, do sal e do açúcar; apontam a melhor maneira de se exercitar, de dormir etc. Em teoria, estes conteúdos seguem o mantra da prestação de serviço e buscam contribuir com a longevidade e o bem-estar da audiência. Na prática, porém, notam-se efeitos colaterais, como o surgimento de novos padrões sociais para o corpo: agora ele deve ser magro e exercitado!

Do ponto de vista da teoria das representações sociais, criada nos anos 1950 pelo psicólogo romeno Serge Moscovici² (1925-2014), verifica-se que a mídia tem levado a uma nova forma de a sociedade pensar o corpo, valorizando sobretudo os contextos de saúde e de beleza.

Do ponto de vista do biopoder, apresentado nos anos 1970 pelo filósofo francês Michel Foucault (1926-1984), seria ingênuo pensar o corpo dessa forma; na perspectiva do autor, é incitando práticas saudáveis na sociedade que a política moderna cria corpos economicamente ativos e politicamente dóceis.

Este texto apresenta duas maneiras de se pensar o corpo: (1) no âmbito do senso comum, por meio das representações sociais; e (2) no âmbito do controle político, pelo biopoder. Ambas no contexto da mídia. O ensaio busca associar estudos da Comunicação Social, da Psicologia Social e da Filosofia por meio de técnica interdisciplinar, usada sempre que topamos com um objeto "cujo lugar não está traçado no grande mapa dos saberes" (POMBO, 2007, p. 6).

$\mathrm{O}$ artigo baseia-se em levantamento bibliográfico, básico ao trabalho científico porque "permite ao pesquisador conhecer o que já se estudou sobre o assunto" (FONSECA, 2002, p. 32). Ele está dividi-

\footnotetext{
${ }^{1}$ Refere-se aos meios de comunicação de massa, como televisão, rádio, jornal e internet. A televisão foi criada em 1925 (ao Brasil, chegou em 1950). 0 rádio surgiu em 1906 (1922, no Brasil). Os jornais surgiram em 1609, mas só ganharam corpo após a Revolução Industrial e atingiram a massa no século 20. A internet é dos anos 1990 (BRIGGS \& BURKE, 2006).

${ }^{2}$ Moscovici (1981, p. 184) parte do conceito de representações coletivas de Durkheim. Para Durkheim, as representações coletivas articulam uma classe de formas intelectuais, incluindo ciência, religião e mitos. Moscovici considera impossível "articular uma tão vasta classe de conhecimento e crenças". Por isso faz duas diferenciações: 1) representações sociais precisam, por um lado, ser compreendidas como uma forma particular de adquirir conhecimento e comunicar o conhecimento adquirido; elas têm sempre duas faces inseparáveis: uma simbólica e a outra icônica; 2) as representações sociais, por outro lado, não podem ser pensadas de forma estática, com função de concentração de massas de palavras ou ideias; representações sociais tornam-se cada vez mais importantes enquanto que os sistemas unificadores (ciência, religião, ideologia e Estado) se tornam mais e mais mutuamente incompatíveis.
} 
do em cinco sessões. A primeira aborda, de forma resumida, o corpo no contexto filosófico, antropológico, sociológico e psicológico. A segunda apresenta a teoria das representações sociais. A terceira destaca estudos da representação social sobre o corpo no âmbito da saúde e da beleza. A quarta trata do corpo no contexto do biopoder. O ensaio conclui que a mídia conduz a uma representação social do corpo passiva em relação ao biopoder.

\section{Corpo: base de nossa relação com o mundo}

O corpo é discutido desde o mundo antigo. Homero o considerava um aglomerado de membros vigorosos; Sócrates dizia que o corpo deveria ser instrumento da alma e da sabedoria. Platão concebia o corpo como prisioneiro da alma; Aristóteles, ao contrário, dizia que a alma dava movimento ao corpo (VERMANT, 1989).

Até hoje a filosofia se esforça para entender o corpo no tempo e no espaço. Merleau-Ponty (2006) diz que o corpo é nosso meio geral de ter um mundo. "Tenho consciência do mundo por meio de meu corpo” (MERLEAU-PONTY, 2006, p. 203).

O corpo também é tema de investigações na Sociologia, na Antropologia e na Psicologia, para citar exemplos básicos de ciências humanas. Vigarello (2003, p. 21) afirma que "o corpo torna-se um objeto suscetível de elucidar épocas e sociedades, podendo, assim, esclarecer um mundo. A diversidade de seus territórios é abundante no seio de cada cultura e de cada época".

Vigarello (2003) pensa o corpo em três faces. A primeira é a do princípio da eficácia (refere-se à sua capacidade de agir sobre os objetos); a segunda é a do princípio de propriedade (posse, pelo corpo, de um espaço e, nele, de um território pessoal); a terceira é o princípio de identidade (manifestação, pelo corpo, de uma interiorização ou de um pertencimento que designa o sujeito).

Le Breton (2006) entende que o corpo está no centro da vida cotidiana. É o corpo que permite ao homem ver, ouvir, saborear, sentir, tocar e colocar significações precisas no mundo que o cerca.

Moldado pelo contexto social e cultural em que o ator se insere, o corpo é o vetor semântico pelo qual a evidência da relação com o mundo é construída: atividades perceptivas, mas também expressão dos sentimentos, cerimoniais dos ritos de interação, conjunto 
de gestos e mímicas, produção da aparência, jogos sutis da sedução, técnicas do corpo, exercícios físicos, relação com a dor, com o sofrimento etc. Antes de qualquer coisa, a existência é corporal (LE BRETON, 2006, p. 7).

O autor acrescenta que é do corpo que nascem e se propagam as significações que fundamentam a existência individual e coletiva da humanidade, e que o corpo é o eixo da nossa relação com o mundo. "O corpo produz sentidos continuamente, e assim insere o homem, de forma ativa, no interior de determinado espaço social e cultural" (LE BRETON, 2006, p. 8).

O antropólogo francês enfatiza que o movimento feminista, que se destacou a partir dos anos 1970, modificou a relação humana com o corpo. Nesse momento, destaca ele (2006, p. 9), "um novo imaginário do corpo, luxuriante, invade a sociedade; nenhuma região da prática social sai ilesa das reivindicações que se desenvolvem na crítica da condição corporal dos atores".

No decorrer do século XX, observa Andrade (2003, p. 124), “a conquista de um corpo saudável e belo passa a ser entendida como um objetivo individual a ser atingido por meio de um exercício intencional de autocontrole, envolvendo força de vontade, restrição e vigilância constantes". É nesse ambiente que a obesidade passa a ser encarada como derrota, falta de disciplina e controle, ao mesmo tempo em que o corpo magro e forte é visto como modelo a ser seguido.

Nas últimas décadas, acrescentam Justo e Camargo (2012, p. 21), o corpo "tem sido evidência tanto na mídia como nas produções científicas". Ele aparece em debates sobre saúde e beleza, gordura e magreza, corpo treinado e sedentário. Para os autores, "o momento que se presencia é marcado pelo culto ao corpo magro, em forma e saudável". "Por um lado ocorre a valorização da exibição de um corpo magro e que reflita saúde; por outro se destaca a epidemia da obesidade, que aumenta na medida em que as pessoas tornam-se cada vez mais sedentárias e com menos tempo para cuidar de si" (JUSTO; CAMARGO, 2012, p. 21).

\section{Representações Sociais: o conhecimento do senso comum}

Moscovici ([1961] 2012, p. 39) não criou um conceito fechado às representações sociais por considerar que elas ocupavam uma "posi- 
ção mista" no "cruzamento de uma série de conceitos sociológicos e psicológicos”. Entretanto, o autor costumava classificá-las como teorias leigas (porque são feitas por cidadãos comuns); como uma forma particular de conhecimento do senso comum (porque são extraídas dos grupos sociais); e como uma espécie de ciência coletiva específica dos não-especialistas (feita pelo povo).

Em uma obra inicial ${ }^{3}$, o autor afirmou que "as representações sociais são entidades quase tangíveis; circulam, se cruzam e se cristalizam continuamente através da fala, do gesto, do encontro no universo cotidiano"; e acrescentou que "a maioria das relações sociais efetuadas, objetos produzidos e consumidos, comunicações trocadas estão impregnadas delas" (MOSCOVICI, 2012, p. 39).

Mais tarde, naquilo que mais se aproxima de um conceito, enfatizou:

Por representações sociais queremos dizer um conjunto de conceitos, afirmações e explicações criado na vida cotidiana, no decurso da comunicação interindividual. Elas são o equivalente, em nossa sociedade, aos mitos e sistemas de crenças das sociedades tradicionais; elas podem até mesmo serem vistas como a versão contemporânea do senso comum (MOSCOVICI, 1981, p. 181).

A função das representações sociais é "tornar uma coisa desconhecida, ou não familiar em geral, em algo familiar" (MOSCOVICI, 1981, p. 186). Isso se dá pelos processos de ancoragem ${ }^{4}$ (liga o objeto estranho a algo familiar) e objetivação $o^{5}$ (faz um conceito se tornar realidade, dando materialidade a ele).

Jodelet (2001, p. 17) entende que as representações sociais são importantes porque "nos guiam no modo de nomear e de definir conjuntamente os diferentes aspectos da realidade diária, no modo de interpretar estes aspectos, tomar decisões e, eventualmente, posicionar-se frente a eles de forma defensiva”.

\footnotetext{
${ }^{3}$ O livro A psicanálise, sua imagem e seu público foi publicado em 1961 e reapresentado em 1976. Moscovici estudou a representação social da psicanálise. Ouviu diversos grupos, de diferentes classes sociais, para saber como a psicanálise era percebida pela sociedade parisiense. No plano geral, seu objetivo era saber como o homem constrói a realidade; no plano específico, queria descobrir como o conhecimento científico é consumido e utilizado pelo homem comum.

${ }^{4}$ A ancoragem é dividida nos fenômenos de classificação (uma forma de dar "um lugar" a determinado objeto; pode ocorrer por generalização ou individualização) e de nomeação (busca dar nome a alguém ou algo) (MOSCOVICI, 1981, p. 192-196).

${ }^{5}$ A objetivação tem três etapas: redução (diminuição mais precisa da comunicação), esquematização estruturante (base das relações padronizadas de conhecimento que formarão as representações sociais) e naturalização (a percepção do grupo é encarada como realidade e materialidade).
} 
Para a autora (2001, p. 22), as representações sociais "são uma forma de conhecimento, socialmente elaborada e partilhada, com um objetivo prático, e que contribui para a construção de uma realidade comum a um conjunto social". Ela acrescenta que, "igualmente designada como saber de senso comum ou saber ingênuo", "esta forma de conhecimento é diferenciada do conhecimento científico. Entretanto, é tida como um objeto de estudo tão legítimo quanto este, devido à sua importância na vida social e à elucidação de processos cognitivos e das interações sociais" (ibid).

Doise (2001) entende que as representações sociais são os princípios que organizam as relações simbólicas entre os atores sociais. "Trata-se de princípios que estruturam as relações simbólicas entre indivíduos ou grupos, constituindo um campo de troca simbólica e uma representação desse campo" (DOISE, 2001, p. 193).

Abric (2003, p. 38) define as representações sociais como "um conjunto organizado e estruturado de informações, crenças, opiniões e atitudes". Segundo o autor, esse conjunto constitui um sistema sociocognitivo particular, composto por um núcleo central (assegura o significado da representação, a organização interna e estabilidade dela) e um sistema periférico (tem a função de concretização, regulação, prescrição de comportamentos, proteção do núcleo central e personalização das representações sociais).

Clémence, Green e Courvoisier (2011, p. 237) dizem que, "para Moscovici, a perspectiva das representações sociais busca analisar a tradução de teorias científicas no senso comum”. Brigido (2015, p. 24) acrescenta que "Moscovici insistiu na importância do conhecimento leigo para as sociedades contemporâneas, nos anos 50, época em que os intelectuais consideravam este tipo de pensamento como inferior ao pensamento científico e tecnológico".

\section{Representação social do corpo: dois estudos}

A teoria das representações sociais norteia estudos em diferentes áreas do conhecimento. No Brasil, é usada sobretudo no âmbito da Educação e da Saúde. O corpo é um objeto muito pesquisado pela perspectiva desta teoria ${ }^{6}$.

\footnotetext{
${ }^{6}$ Para criar a teoria, Moscovici (2012) valeu-se da psicologia de Piaget (1896-1980), que estudou as representações do mundo das crianças; da antropologia de Lévy-Bruhl (1857-1939), que teorizava sobre crenças, mitos e pensamento coletivo; e, com maior destaque, recorreu à sociologia de Durkheim (1858-1917), para quem o coletivo age sobre os indivíduos.
} 
Neste ensaio destacaremos duas pesquisas sobre a representação social do corpo, ambas feitas por pesquisadores do Laboratório de Psicologia Social da Comunicação e Cognição (Laccos) da Universidade Federal de Santa Catarina (UFSC). O objetivo é ter exemplos de como o público pensa o corpo.

O primeiro dos estudos ouviu 79 pessoas $^{7}$ por meio das técnicas de evocação livre e grupo focal; o trabalho procurou identificar as representações sociais do corpo nos contextos da saúde e da beleza.

Nas evocações livres, os pesquisadores verificaram que as palavras mais citadas sobre o corpo no contexto saúde foram bem-estar, vida e mente; no contexto beleza os participantes salientaram palavras como aparência e expressão.

Nos grupos focais, no contexto da saúde as categorias com maior frequência foram doença, atividade física, cuidados, equilíbrio, alimentação e bem-estar. No contexto da beleza, as categorias que ocorreram com maior frequência foram sociedade, autoimagem, atividade física, aparência, saúde e beleza.

Compilando os resultados, os pesquisadores concluíram que no contexto saúde o corpo é pensado a partir da individualidade:

É contemplado em termos de cuidados com a saúde de um corpo orgânico, o qual é o veículo da vida e necessita de equilíbrio. No contexto beleza, a ideia de corpo está ancorada na interação do indivíduo com o mundo; na forma como ele se apresenta aos demais, naquilo que pode adquirir do mundo a partir do corpo (CAMARGO; JUSTO; ALVES; SCHLÖSSER, 2013, p. 45).

O outro estudo pesquisou as representações sociais do corpo entre modelos fotográficos e não modelos $^{8}$. O objetivo era perceber como os dois grupos pensam o corpo do ponto de vista da beleza física.

Entre os modelos, os elementos mais citados foram felicidade, inveja, popularidade, conquista, influência, modificação corporal, saúde, atração, sucesso, qualidade de vida, magro, padrões, sedução e ju-

\footnotetext{
${ }^{7}$ Participaram do estudo 40 jovens ( 20 homens e 20 mulheres, entre 18 e 25 anos) e 39 adultos ( 20 homens e 19 mulheres, entre 41 e 58 anos). Divididos em grupos de cinco pessoas, os participantes foram estimulados a falar (grupo focal) e a responder questionários (evocação de palavras) sobre "corpo" depois de assistirem a dois vídeos sobre o tema. Os dois vídeos tinham cinco minutos de duração; um deles valorizava o aspecto saúde; o outro, o aspecto beleza.

${ }^{8}$ Participaram 120 pessoas (60 homens e 60 mulheres). Metade do grupo de modelos fotográficos e metade de não modelos. Foi utilizado um instrumento online autoaplicável, com respostas abertas e fechadas, visando identificar os principais atributos relacionados à beleza física.
} 
ventude. Entre os não modelos os elementos predominantes foram popularidade, conquista, influência, modificação corporal, atração, padrões, juventude e sedução.

Os pesquisadores concluíram que a beleza física volta-se prioritariamente para o aspecto da atração interpessoal, tanto para o sexo feminino quanto para o sexo masculino, verificado pelos elementos conquista, atração, sedução e popularidade.

\begin{abstract}
Para ambos os sexos, a beleza física transpõe a saúde ou o cuidado consigo mesmo, enfocando diretamente as possibilidades de atratividade, se apresentando como componentes centrais nas representações sociais da beleza física no presente estudo (CARMARGO; SCHLÖSSER, 2015, p. 280).
\end{abstract}

Em síntese, os dois estudos mostram que, incitados a falar sobre o corpo no contexto da saúde e da beleza, os participantes demonstraram preocupações com peso, bem-estar, longevidade, poder de atração e outros temas da esfera cotidiana. Não pensaram o corpo no contexto do biopoder, como alvo das políticas da vida. Na perspectiva de Foucault $(2005 ; 2012 ; 2013)$ é incitando práticas saudáveis na sociedade que o biopoder cria corpos economicamente ativos (a serviço do capitalismo) e politicamente dóceis (para não oferecer resistência ao poder). Em nosso tempo, esta incitação ao cuidado de si ocorre majoritariamente por meio da mídia, em programas que esquadrinham o corpo humano. Esse tipo de programa está presente tanto no âmbito do entretenimento (como Encontro com Fátima, da Rede Globo) quanto do jornalismo (como Fantástico, dominical, e Bem-Estar, programa diário sobre saúde e bem estar exibido na mesma emissora).

\title{
Biopoder: o corpo como alvo político
}

Foucault (2012) pensa o corpo como o mecanismo onde se exerce o controle sobre a vida. Isso se dá pelo que o autor chamou de biopoder. Trata-se de uma forma de governar a vida posta em prática a partir do século XVII.

O biopoder se divide em dois eixos: as disciplinas, por meio das quais se opera o governo do corpo dos indivíduos; e a biopolítica, através da qual se esquadrinha o corpo social (a população) como um todo.

Foucault (2012) diz que o poder soberano, que prevaleceu até o 
século XVII, governava pela morte (direito de causar a morte). Esse poder foi substituído por outra forma de governo, centrada na vida (dever de causar a vida).

No caso das disciplinas, que se verifica no ocidente a partir do século XVII, a nova forma política centrou-se no corpo como máquina. Focava seu adestramento. Agia na ampliação de suas aptidões, na extorsão de suas forças, no crescimento paralelo de sua utilidade econômica e docilidade política, na sua integração em sistemas de controle eficazes e econômicos.

O corpo humano entra numa maquinaria de poder que o esquadrinha, o desarticula e o recompõe. Uma anatomia política, que é também igualmente uma mecânica do poder, está nascendo; ela define como se pode ter poder sobre o corpo dos outros, não simplesmente para que façam o que se quer, mas para que operem como se quer, com as técnicas, segundo a rapidez e a eficácia que se determina. A disciplina fabrica assim corpos submissos e exercitados, corpos dóceis. A disciplina aumenta as forças do corpo em termos econômicos de utilidade e diminui essas mesmas forças em termos políticos de obediência (FOUCAULT, 2013, p. 133-134).

No caso da biopolítica, que se nota a partir da segunda metade do século XVIII, a política centrou-se no coletivo. Ou, como define o autor, no corpo transpassado pela mecânica do ser vivo como suporte dos processos biológicos; no controle da proliferação, dos nascimentos, da mortalidade, do nível de saúde, da duração da vida, da longevidade com todas as condições que podem fazê-los variar.

A disciplina tenta reger a multiplicidade dos homens na medida em que essa multiplicidade pode e deve redundar em corpos individuais que devem ser vigiados, treinados, utilizados, punidos. E, depois, a nova tecnologia (biopolítica) que se instala se dirige à multiplicidade dos homens, não na medida em que eles se resumem em corpos, mas na medida em que ela forma, ao contrário, uma massa global, afetada por processos de conjunto que são próprios da vida, que são processos como o nascimento, a morte, a produção, a doença (FOUCAULT, 2005, p. 289).

O autor observa que essa tecnologia de poder criou mecanismos que tratam, sobretudo, de previsões, estimativas estatísticas e medições globais. Em outras palavras, a biopolítica implantou regulações que buscam otimizar um estado de vida no povo. 
Foucault (2012) entende que a principal função das disciplinas e da biopolítica é produzir corpos economicamente ativos e politicamente dóceis.

Este biopoder, sem a menor dúvida, foi elemento indispensável ao desenvolvimento do capitalismo, que só pôde ser garantido à custa da inserção controlada dos corpos nos aparelhos de produção e por meio de um ajustamento de fenômenos de população aos processos econômicos (FOUCAULT, 2012, p. 132).

\section{Considerações finais}

Teóricos da Comunicação Social afirmam, desde o início do século XX, que a mídia exerce poder sobre a audiência ${ }^{9}$, pautando debates e criando tendências na sociedade. Uma síntese desse poder midiático está em Luhmann (2005), que afirma: "aquilo que sabemos sobre a nossa sociedade, ou mesmo sobre o mundo no qual vivemos, o sabemos pelos meios de comunicação" (LUHMANN, 2005, p. 15).

Para Moscovici (1981), teórico da Psicologia Social, os meios de comunicação de massa são determinantes para a construção de representações sociais. O autor entende que essa forma de comunicação acelerou a tendência de incompatibilidade entre ciência, religião, ideologia e Estado, e que isso aumentou a necessidade de uma sutura entre (1) o status abstrato de nossas ciências e nossas crenças gerais e (2) nossas atividades concretas como indivíduos sociais. "Em outras palavras, há uma necessidade cada vez maior de se continuar reconstituindo o senso comum, aquela soma de conhecimentos que constitui o substrato de imagens e significados sem os quais nenhuma coletividade pode operar" (MOSCOVICI, 1981, p. 185).

Jodelet (2001, p. 30) observa que Moscovici (1981) pensava a comunicação em três níveis: nível da emergência, nível dos processos de formação das representações e nível das dimensões das representações.

O primeiro nível diz respeito às condições que afetam os aspec-

\footnotetext{
${ }^{9}$ As primeiras teorias da área surgiram a partir do uso do rádio por Hitler. As primeiras foram a hipodérmica (a informação atinge a massa de maneira idêntica e sem resistência), a de Lasswell (o público é uma massa passiva que só reage aos estímulos) e a da persuasão (o conteúdo é absorvido de maneira distinta pelo público, de acordo com perspectivas pessoais). As seguintes foram a teoria empírica de campo (a mídia tem uma influência limitada sobre a massa, como a escola, a Igreja ou a política), a funcionalista (foca o papel da mídia na sociedade, não seus efeitos), a crítica (vê a mídia como instrumento de influência capitalista) e a culturológica (a mídia não produz cultura de massa, mas se baseia em padrões sociais existentes, que surgem da cultura) (WOLF, 1995).
} 
tos cognitivos. Entre essas condições estão a dispersão e a defasagem das informações relativas ao objeto representado, o foco sobre certos aspectos do objeto, a pressão à inferência referente à necessidade de agir, de tomar posição ou de obter a adesão dos outros.

O segundo nível refere-se à objetivação e à ancoragem, os dispositivos que tornam familiar o objeto estranho. Elas explicam a interdependência entre a atividade cognitiva e suas condições sociais de exercício, nos planos de organização de conteúdo e das significações.

O terceiro nível tem a ver com a edificação da conduta: opinião, atitude e estereótipo, sobre os quais intervêm os sistemas de comunicação midiáticos. Estes sistemas operam pela difusão (relacionada à formação das opiniões), pela propagação (relacionada à formação das atitudes) e pela propaganda (refere-se à formação de estereótipos). "Assim, a comunicação social, sob seus aspectos interindividuais, institucionais e midiáticos, aparece como condição de possibilidade e de determinação das representações e dos pensamentos sociais" (JODELET, 2001, p. 30).

Clémence, Green e Courvoisier (2011) observam que, devido à homologia entre a imagem que a imprensa produz e aquela que manifestam as pessoas entrevistadas, a formação de uma representação social passa por trocas e por influências recíprocas entre os jornais e seus leitores. "Sem a reação destes últimos, é provável que o lançamento de uma nova informação científica atualizada, ou uma reatualização permaneça sem repercussão" (CLÉMENCE; GREEN; COURVOISIER, 2011, p. 142).

Considerando que os meios de comunicação de massa exercem poder sobre o público, como mostram teorias da Comunicação Social; que ajudam na formação das representações sociais e do pensamento social, como reconhece a Psicologia Social de Moscovici (1981) e (Jodelet (2001); e que otimizam um estado de vida na população, como argumenta a Filosofia de Foucault, pode-se concluir que:

(1) ao promoverem programas que valorizam os cuidados com o corpo, os meios de comunicação de massa ajudam a criar uma representação social do corpo como algo que deve ser constantemente cuidado e melhorado, tanto no âmbito individual (sujeito) quanto no âmbito coletivo (sociedade);

(2) essa representação social do corpo tem uma face ingênua, pois assimila passivamente os objetivos deste biopoder (criar corpos economicamente ativos e politicamente dóceis); 
(3) mídia, sob o mantra da prestação de serviço para aumentar a longevidade e o bem-estar da audiência, massifica as políticas que agem sobre o corpo e que buscam otimizar um estado de vida;

(4) há uma diferença gritante entre aquilo que o público pensa sobre o corpo a partir da mídia (como algo que deve ser cuidado e melhorado) e aquilo que o biopoder procura incitar por meio da mídia (corpos ativos a serviço do capital).

\section{REFERÊNCIAS}

ABRIC, Jean-Claude. Abordagem estrutural das representações sociais: desenvolvimentos recentes. In: P.H.F. Campos; M.C.S. Loureiro (org). Representações sociais e práticas educativas. Goiânia: UCG.

ANDRADE, Sandra dos Santos. Saúde e beleza do corpo feminino algumas representações no Brasil do Século XX. Porto Alegre, v. 9, n. 1, 2003.

BRIGGS, Asa; BURKE, Peter. Uma história social da mídia: de Gutenberg à internet. 2. ed. Rio de Janeiro: Zahar, 2006.

CAMARGO, Brigido. Serge Moscovici: um precursor inovador na psicologia social. Memorandum, 28, 2015.

CAMARGO, Brigido; JUSTO, Ana Maria; ALVES, Catarina Durante Bergue; SCHLOSSER, Adriano. Efeitos de contexto interacional e comunicação nas representações sociais sobre o corpo. Psicologia e Saber Social, v. 2, 2013.

CLÉMENCE, Alain; GREEN, Eva; COURVOISIER, Nelly. Comunicação e ancoragem: a difusão e a transformação das representações. In: ALMEIDA, Angela Maria de Oliveira; SANTOS, Maria de Fátima; TRINDADE, Zeidi Araújo (org). Teoria das representações sociais: 50 anos. Brasília: Technopolitk, 2011.

DOISE, Weise. Atitudes e representações sociais. In: JODELET, Denise (org). As representações sociais. Rio de Janeiro: EdUERJ, 2001.

FONSECA, João José. Metodologia da pesquisa científica. Fortaleza: UEC, 2002. Apostila. 
FOUCAULT, Michel. História da sexualidade I: a vontade de saber; tradução de Maria Thereza da Costa Albuquerque e J. A. Guilhon Albuquerque. 22. ed. Rio de Janeiro: Graal, 2012.

. Vigiar e punir: história da violência nas prisões; tradução de Raquel Ramalhete. 41. ed. Petrópolis: Vozes, 2013.

Em Defesa da Sociedade. São Paulo: Martins Fontes, 2005.

JODELET, Denise. Representações Sociais: um domínio em expansão. In: JODELET, Denise (org). As representações sociais. Rio de Janeiro: EdUFRJ, 2001.

JUSTO, Ana Maria; CAMARGO, Brigido. Corpo e cognições sociais. Liberabit, 19 (1), Lima, 2013.

LE BRETON, David. A sociologia do corpo. 2 ed; tradução de Sônia Fuhrmann. Petrópoles: Vozes, 2006.

LUHMANN, Niklas. A realidade dos meios de comunicação; tradução de Ciro Marcondes Filho. São Paulo: Paulus, 2005.

MERLEAU PONTY, Maurice. Fenomenologia da percepção. $3^{a}$ ed. São Paulo: Martins Fontes, 2006.

MOSCOVICI, Serge. A psicanálise, sua imagem e seu público. Petrópolis: Vozes, [1961] 2012. . On social representation. In: FORGAS, Joseph (org). Social cognition. London: Academic Press, 1981.

POMBO, Olga. Epistemologia da Interdisciplinaridade. In: Interdisciplinaridade, Humanismo e Universidade. Cátedra Humanismo Latino. Porto, 2007.

SCHLÖSSER, Adriano; CAMARGO, Brigido. Representações sociais da beleza física para modelos fotográficos e não modelos. Psico Porto Alegre, 46 (2), 2015. 
VERNANT, Jean Pierri. As origens do pensamento Grego; tradução de Isis Borges da Fonseca. Rio de Janeiro: Bertrand Brasil, 1989.

VIGARELLO, Georges. A história e os modelos do corpo. Pro-Posições. Unicamp, v.14, n.2, 2003.

WOLF, Mauro. Teorias da comunicação. 5. ed. Lisboa, 1995. 
AÇÃO MIDIÁTICA, n.11. Jan/jun. 2016. Curitiba. PPGCOM-UFPR. ISSN 2238-0701

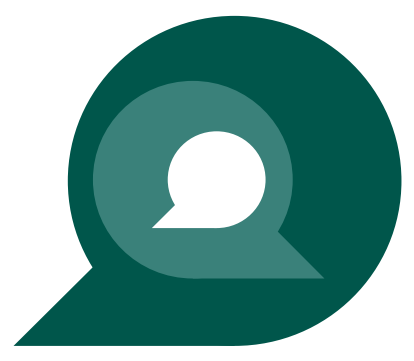

